\title{
Pelatihan Inovasi Makanan Tradisional Serabi Ragam Rasa (SERAGAM) Untuk Meningkatkan Daya Beli Masyarakat Desa Harapan
}

\author{
Ika Triwati ${ }^{*}$, Siti Fatimah ${ }^{2}$ \\ 1, Prodi Teknik Sipil, Akademi Teknologi Industri Dewantara Palopo \\ 2, Prodi Teknik Elektronika, Akademi Teknologi Industri Dewantara Palopo \\ ${ }^{1}$ ikatriwati@atidewantara.ac.id, ${ }^{2}$ stfatimah@atidewantara.ac.id
}

\begin{abstract}
Abstrak
Dalam rangka terciptanya peluang usaha kecil masyarakat yang bergerak di sektor ekonomi, Dosen Akademi Teknologi Industri Dewantara Palopo bersama mahasiswa melakukan workshop pelatihan pembuatan Serabi Ragam Rasa (SERAGAM) dengan menggunakan power point dan praktek pembuatan langsung kepada masyarakat Desa Harapan Kecamatan Mappedeceng, Kabupaten Luwu Utara. Dengan kegiatan ini diharapkan dapat meningkatkan kreativitas inovatif mahasiswa dan masyarakat dalam rangka bereksperimen serta menemukan hasil karya yang bermanfaat dan tepat guna. Masyarakat dapat mengoptimalkan pemanfaatan SERAGAM (Serabi Ragam Rasa) ini diharapkan dapat menjadi permen favorit sehingga laris di pasaran dengan bentuk yang lucu dan menarik. Selain itu, masyarakat juga diharapkan termotivasi untuk mengembangkan SERAGAM (Serabi Ragam Rasa) untuk dijual di pasaran. Metode kegiatan pengabdian ini adalah metode ceramah untuk memberi penjelasan tentang pembuatan SERAGAM (Serabi Ragam Rasa), metode praktik untuk pelatihan (workshop) pembuatan SERAGAM (Serabi Ragam Rasa), dan metode diskusi untuk membahas tentang keberlanjutan usaha SERAGAM (Serabi Ragam Rasa). Kegiatan pengabdian pada masyarakat ini berupa workshop pembuatan SERAGAM (Serabi Ragam Rasa) yang dilaksanakan pada hari sabtu, tanggal 16 Januari 2021 di Desa Harapan Kecamatan Mappedeceng, Kabupaten Luwu Utara. Workshop ini dilakukan melalui dua tahap yaitu tahap pra produksi dan tahap produksi, mengingat banyaknya manfaat yang dapat diperoleh masyarakat dari kegiatan ini, pelatihan dapat dilakukan sebanyak mungkin dan berkelanjutan dengan disertai pengembangkan dari materi pelatihan itu sendiri. Kegiatan pelatihan pembuatan SERAGAM (Serabi Ragam Rasa) sangat membantu masyarakat dalam mengembangkan kreativitas khususnya ibu - ibu yang ada di Desa Mappedeceng yang notabene pekerjaan sehari-harinya Ibu Rumah Tangga, mereka bisa membuat peluang usaha di bidang ini.
\end{abstract}

Kata Kunci: seragam, tepung beras, ragi, fermipan, pelatihan

\section{Pendahuluan}

Anak muda zaman sekarang tidak lepas dari yang namanya jajanan. Jajanan sudah menjadi makanan ringan sehari-hari dan telah menjadi budaya masyarakat. Salah satu contoh jajanan yang banyak dibeli anak muda zaman sekarang adalah serabi. Serabi 
adalah hidangan penutup dengan rasa manis yang terbuat dari tepung beras bersama tepung terigu/gandum, ragi instan/fermipan, sodakue, telur, santan, dan garam.

Serabi dapat disajikan dalam berbagai kesempatan dengan berbagai variasi rasa, bentuk dan tekstur, dimana sebelumnya serabi dibekukan dalam cetakan berbagai ukuran. Indonesia sebagai Negara agrarais menghasilkan berbagi macam produk olahan pertanian yang salah satunya adalah padi. padi merupakan jenis makanan yang dapat diolah menjadi beras/nasi baik makanan tradisional maupun modern.

Selain digunakan menjadi nasi, beras juga dapat diolah menjadi berbagai macam makanan dan menciptakan berbagai macam ragam rasa seperti serabi. Berdasarkan uraian permasalahan diatas maka penulis menciptakan inovasi makanan yang diberi nama SERAGAM. SERAGAM (serabi ragam rasa) merupakan makanan yang berbahan dasar beras yang dicampur dengan berbagai macam bahan. Serabi ini dikreasikan dengan berbagai rasa seperti keju, dan berbagai macam rasa lainnya sesuai keinginan.

\section{Metode Pelaksanaan}

Kegiatan pengabdian pada masyarakat ini berupa workshop pembuatan SERAGAM (Serabi Ragam Rasa) yang dilaksanakan pada hari sabtu, tanggal 16 Januari 2021 di Desa Harapan Kecamatan Mappedeceng, Kabupaten Luwu Utara. Tabel kelayakan usaha SERAGAM

\begin{tabular}{lccc}
\hline Aset tetap & Harga & Umur ekonomis & Depresiasi satu tahun \\
\hline Cetakan & Rp 1.250.000 & 8 tahun & Rp 39.000 \\
Kompor & Rp 600.000 & 3 tahun & Rp 37.500 \\
\hline & Beban aset tetap & & Rp 76.500 \\
\hline
\end{tabular}

Berdasarkan Break Event Point ialah titik impas dimana posisi jumlah pendapatan dan biaya sama atau seimbang sehingga tidak terdapat keuntungan tau kerugian. Harga pokok produk SERAGAM sebesar Rp. 5.000 per unit. Adapun harga jual dari produk SERAGAM sebesar Rp 10.000 dan kuantitas produksi sebesar 4800 unit per tahun.

$$
\text { Price } B E P=\frac{\text { beban aset tetap }+ \text { harga pokok }}{\text { output }}=\frac{R p 76,500+R p 5,000}{R p 4,800}=16
$$

Quantity $B E P=\frac{\text { beban aset tetap }}{\text { harga jual }- \text { harga pokok }}=\frac{R p 76,500}{R p 10,000-R p 5,000}=15,3$ unit, atau menjadi 16 unit

Metode kegiatan pengabdian ini adalah metode ceramah untuk memberi penjelasan tentang pembuatan SERAGAM (Serabi Ragam Rasa), metode praktik untuk pelatihan (workshop) pembuatan SERAGAM (Serabi Ragam Rasa), metode diskusi untuk membahas tentang keberlanjutan usaha SERAGAM (Serabi Ragam Rasa). 


\section{Hasil dan Pembahasan}

Kegiatan pengabdian pada masyarakat ini berupa workshop pembuatan SERAGAM (Serabi Ragam Rasa) yang dilaksanakan pada hari sabtu, tanggal 16 Januari 2021 di Desa Harapan Kecamatan Mappedeceng, Kabupaten Luwu Utara. Workshop ini dilakukan melalui dua tahap yaitu:

\section{Pra Produksi}

Pada tahap ini dilakukan survey lokasi penjualan bahan baku dana peralatan produk SERAGAM serta penentuan dan pemilihan rasa yang akan dibuat dalam bentuk cetakan.

\section{Produksi SERAGAM}

Pada tahap ini dilakukan proses produksi SERAGAM dengan rincian sebagai berikut; Alat: Kompor, panci, sendok, dan cetakan.

Bahan: 50 grm tepung beras, 150 grm terigu/gandum, 1 sdt munjung ragi instan/fermipan, $1 / 2$ sdt soda kue, 1 butir telur,250 $\mathrm{ml}$ santan, sejumput garam dan keju.

\section{Cara pembuatan SERAGAM}

1. Campur semua bahan kecuali garam dan keju, aduk sampai tidak bergerindil lagi, jika perlu boleh disaring menggunakan saringan kawat

2. setelah dirasa tidak bergerindil lagi, tutup adonan dan diamkan selama 60 menit

3. setelah 60 menit adonan akan berbusa tambahkan garam dan aduk kembali

4. panaskan Teflon dengan api kecil, panaskan satu centong adonan

5. boleh ditutup agar matangnya merata. Saat setengah matang taburkan ceres atau toping yang diinginkan jika tidak menggunakan kinca.

6. jangan digoyang teflonnya dan tidak perlu dibalik, setelah masak akan kelihatan lubang-lubang tanda didalamnya sudah bersarang setelah matang, angkat kemudian taburi dengan keju secukupnya dan SERAGAM siap disajikan.

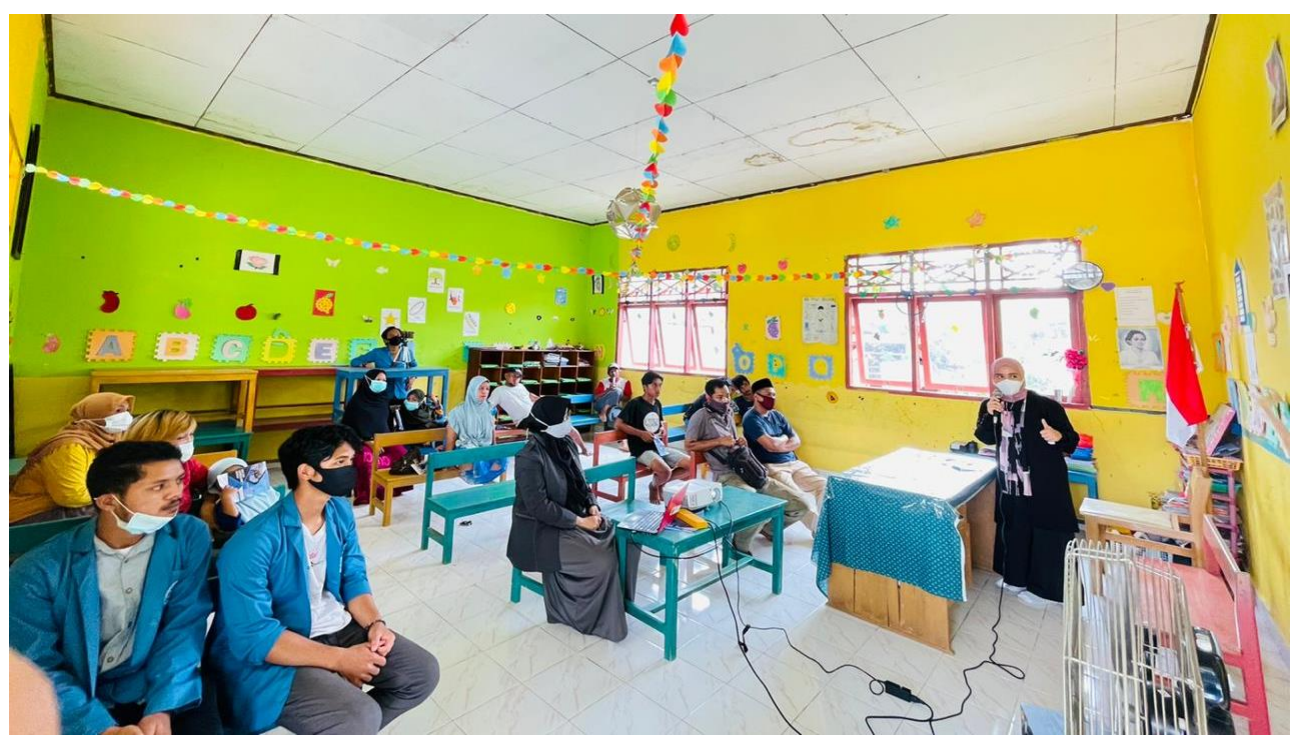

Gambar 1. penjelasan tentang cara pembuatan SERAGAM (Serabi Ragam Rasa) 
Vol. 2, No. 2, Mei 2021

ISSN 2721-4834

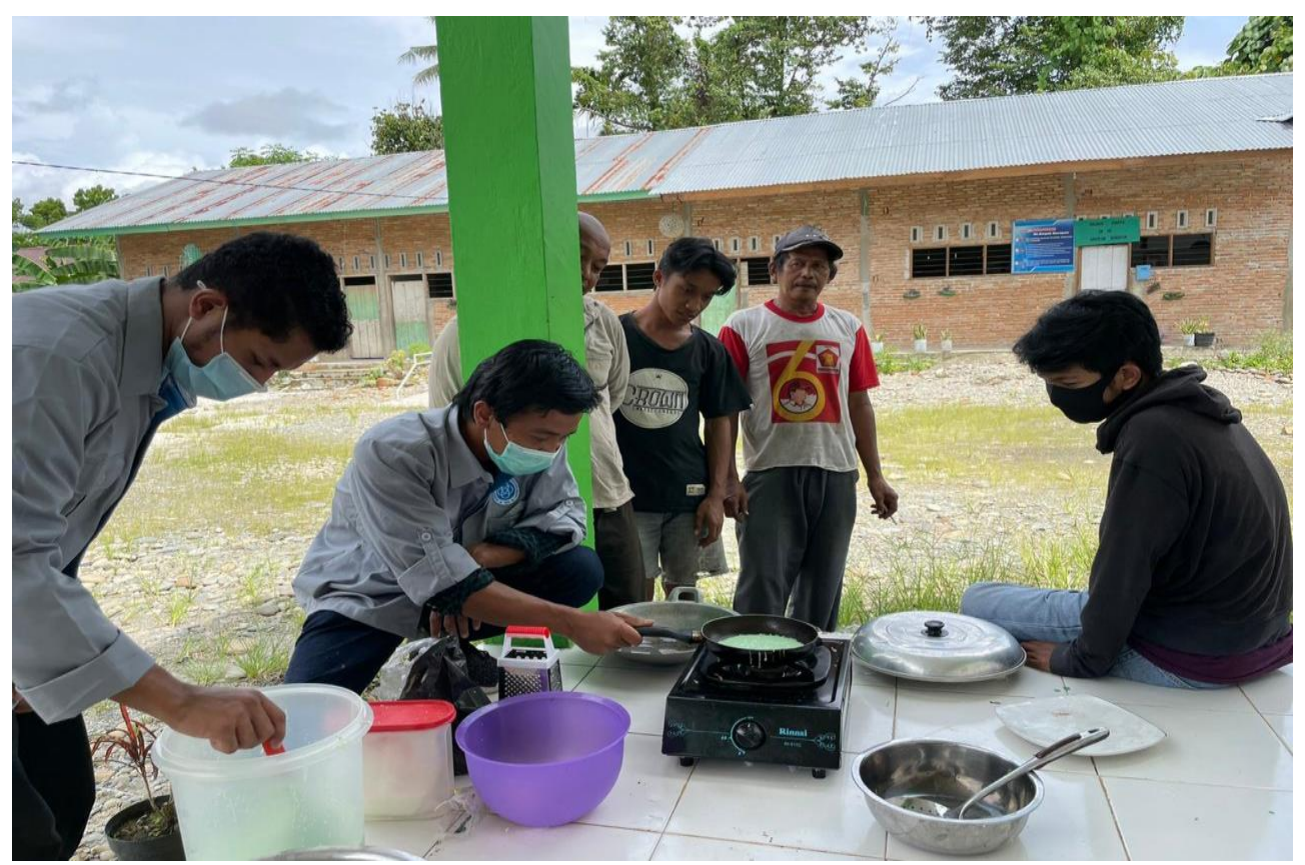

Gambar 2. proses pembuatan SERAGAM (Serabi Ragam Rasa)

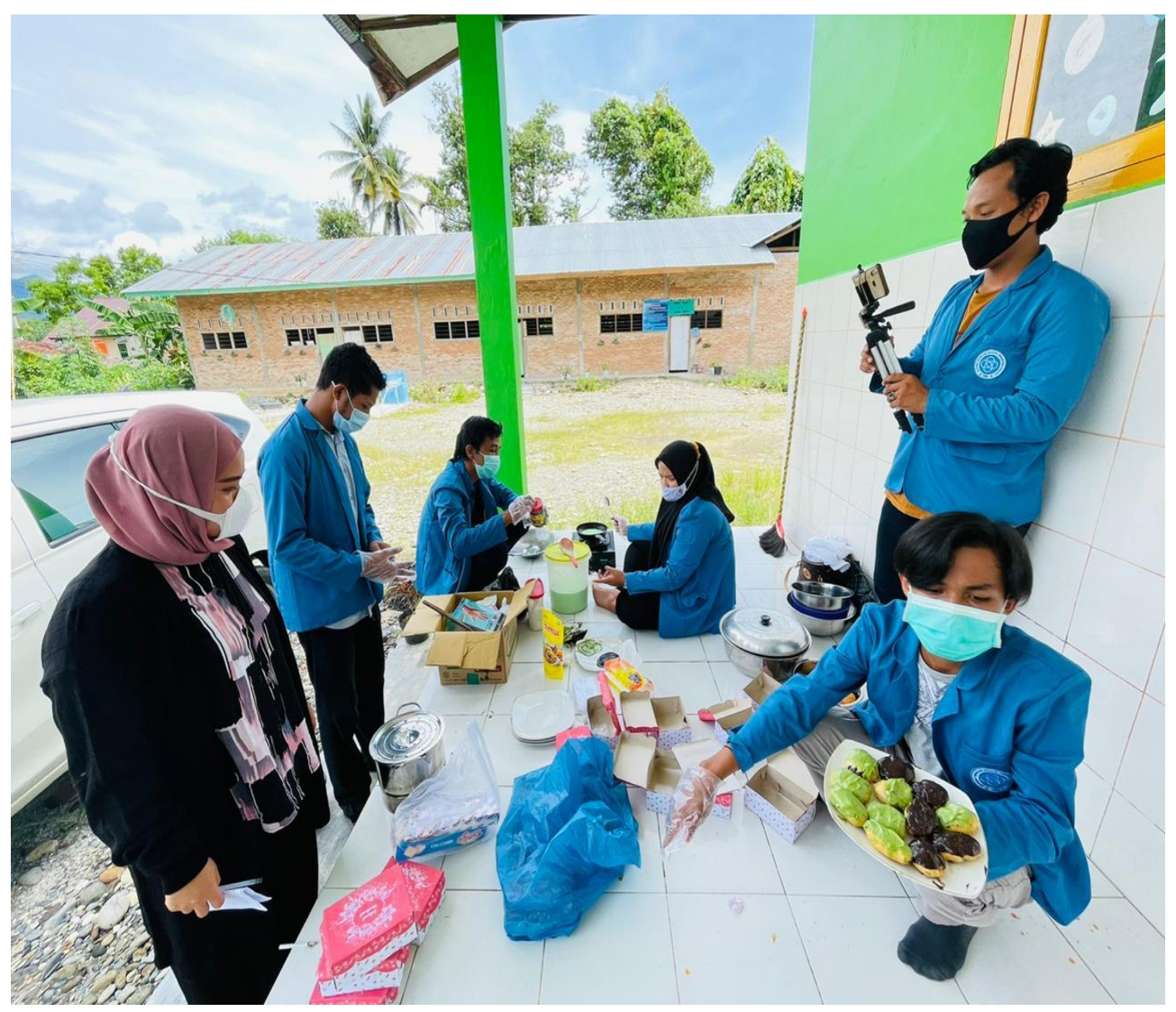

Gambar 3. Proses Penyajian SERAGAM (Serabi Ragam Rasa) 

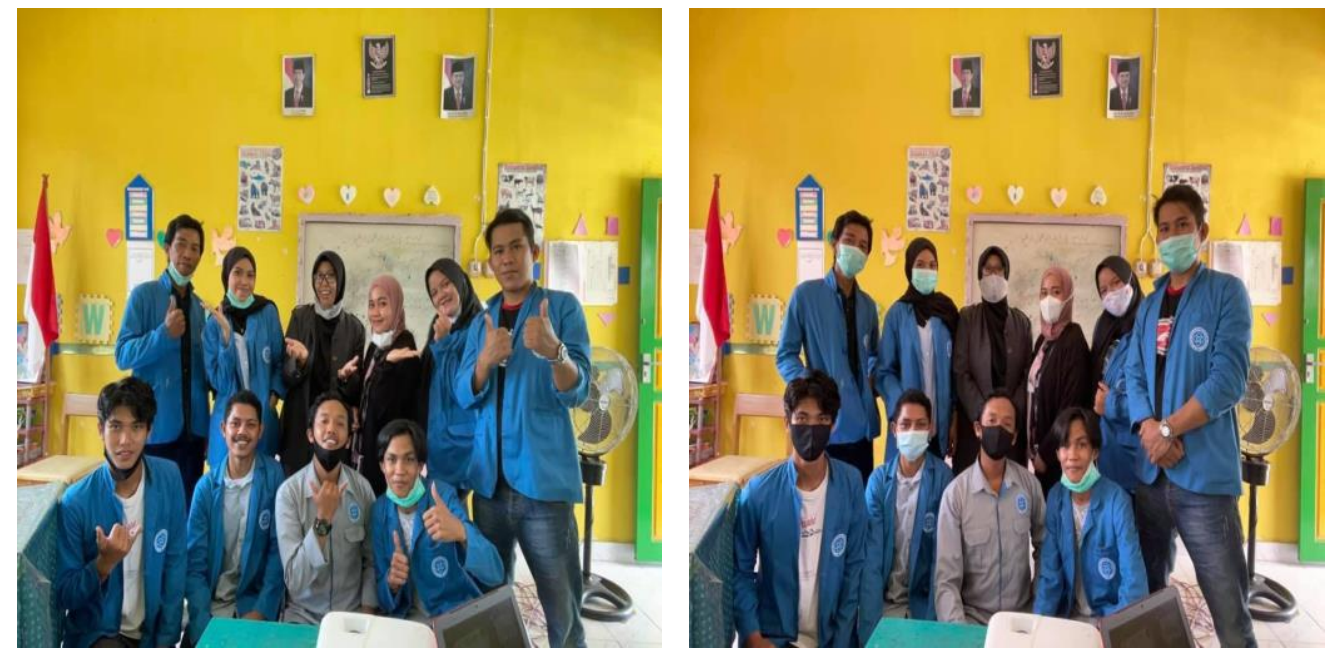

Gambar 4. Dosen dan Mahasiswa yang turut berpartisipasi pada pelatihan

\section{Kesimpulan}

Kegiatan pelatihan pembuatan SERAGAM (Serabi Ragam Rasa) sangat membantu masayrakan dalam mengembangkan kreativitas khususnya ibu-ibu yang ada di Desa Mappedeceng yang notabene pekerjaan sehari-harinya Ibu Rumah Tangga, mereka bisa membuat peluang usaha di bidang ini.

Mengingat banyaknya manfaat yang dapat diperoleh masyarakat dari kegiatan ini, pelatihan dapat dilakukan sebanyak mungkin dan berkelanjutan dengan disertai pengembangkan dari materi pelatihan itu sendiri.

\section{Ucapan Terimakasih}

Dalam penyusunan ini kami tidak lepas dari bantuan berbagai pihak sehingga kegiatan ini dapat terlaksana dengan baik. Untuk itu kami mengucapkan terima kasih kepada Dr. Suaedi, M.Si., selaku Direktur Akademi Teknologi Industri Dewantara Palopo yang telah menyetujui pelaksanaan program pengabdian kepada masyarakat dengan judul SERAGAM (Serabi Ragam Rasa) di Desa Harapan Kecamatan Mappideceng Kabupaten Luwu Utara. Kami juga berterimakasih kepada berbagai pihak yang telah banyak membantu mengarahkan, membimbing, dan memberikan dorongan sampai pengabdian kepada masyarakat ini dapat berjalan dengan lancar.

\section{Referensi}

Syarifuddin, D., Noor, C. M., \& Rohendi, A. (2018). Memaknai Kuliner LokalSebagai Daya Tarik Wisata Kota Bandung. JURNAL ABDIMAS BSI Jurnal Pengabdian Kepada Masyarakat, 1(1), 55-64. https://ejournal.bsi.ac.id/ejurnal/index.php/abdimas/article/view/2866

Holinesti, R., \& Isnaini, I. (2020). Analisis Kualitas Serabi Yang Dihasilkan Dari Substitusi Labu Kuning. Jurnal Pendidikan Tata Boga dan Teknologi, 1(2), 47-53. http://boga.ppj.unp.ac.id/index.php/jptb/article/view/30

Faza, S. S. (2019). Fotografi Dokumenter "Surabi” melalui Metode EDFAT. Pantun Jurnal Ilmiah Seni Budaya, 4(1), 62-73. https://jurnal.isbi.ac.id/index.php/pantun/article/view/1113 